\title{
Genetic Algorithms in the Design AND Planning of ProduCtion System
}

\author{
Milan Gregor, Martin Krajčovič, Jozef Hnát, Viktor Hančinsky
}

University of Zilina, Univerzitna 8215/1, 01026 Zilina, Slovak Republic

\begin{abstract}
The authors deal with genetic algorithms as an effective tool for design and planning of production system. Genetic algorithms are part of evolutionary algorithms, which are rapidly spreading into all main fields of product and production system design and optimization. The main advantage of genetic algorithms is its ability to search large and complex set of solutions and to find acceptable solution in acceptable time. In the paper authors describe their basic principles algorithm itself, its steps and possible rules used within it. Several examples of utilization are presented, and subsequently we focus on applications developed at the Department of Industrial engineering, University of Zilina. Particularly we focus on line balancing, scheduling and production system design.
\end{abstract}

Keywords: genetic algorithm; production system; production layout; line balancing; scheduling
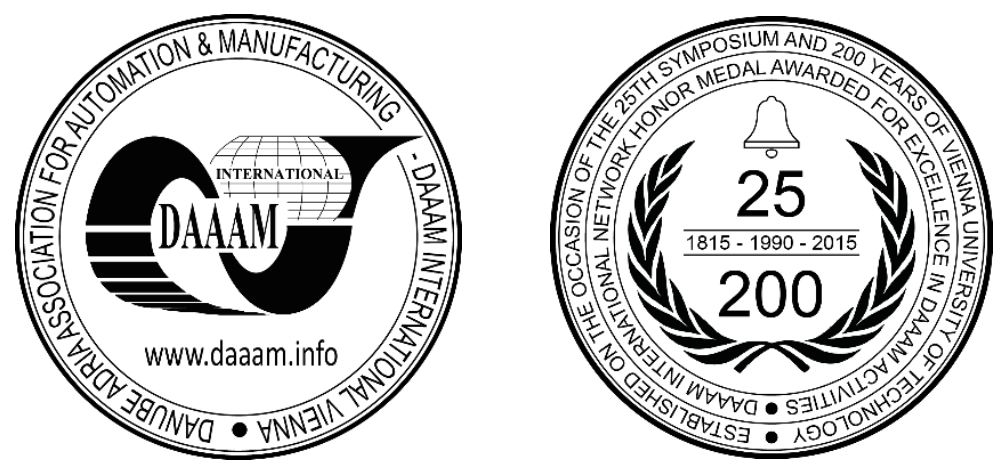

This Publication has to be referred as: Gregor, M[ilan]; Krajcovic, M[artin]; Hnat, J[ozef] \& Hancinsky, V[iktor] (2016). Genetic Algorithms in the Design and Planning of Production System, Proceedings of the 26th DAAAM International Symposium, pp.0494-0500, B. Katalinic (Ed.), Published by DAAAM International, ISBN 978-3-90273407-5, ISSN 1726-9679, Vienna, Austria

DOI: $10.2507 / 26$ th.daaam.proceedings.066 


\section{Principle of genetic algorithms}

Genetic algorithms are based on the Darwinian principle of natural evolution that was described in his book "On the Origin of Species by Means of Natural Selection, or the Preservation of Favored Races in the Struggle for Life "(1859). This publication brought a revolution of the perception of life on Earth. Together with other disciples they gradually formulated the laws of classical genetics and the basic principles of reproduction. In the twentieth century these principles expanded into other, than biological fields [14], [15].

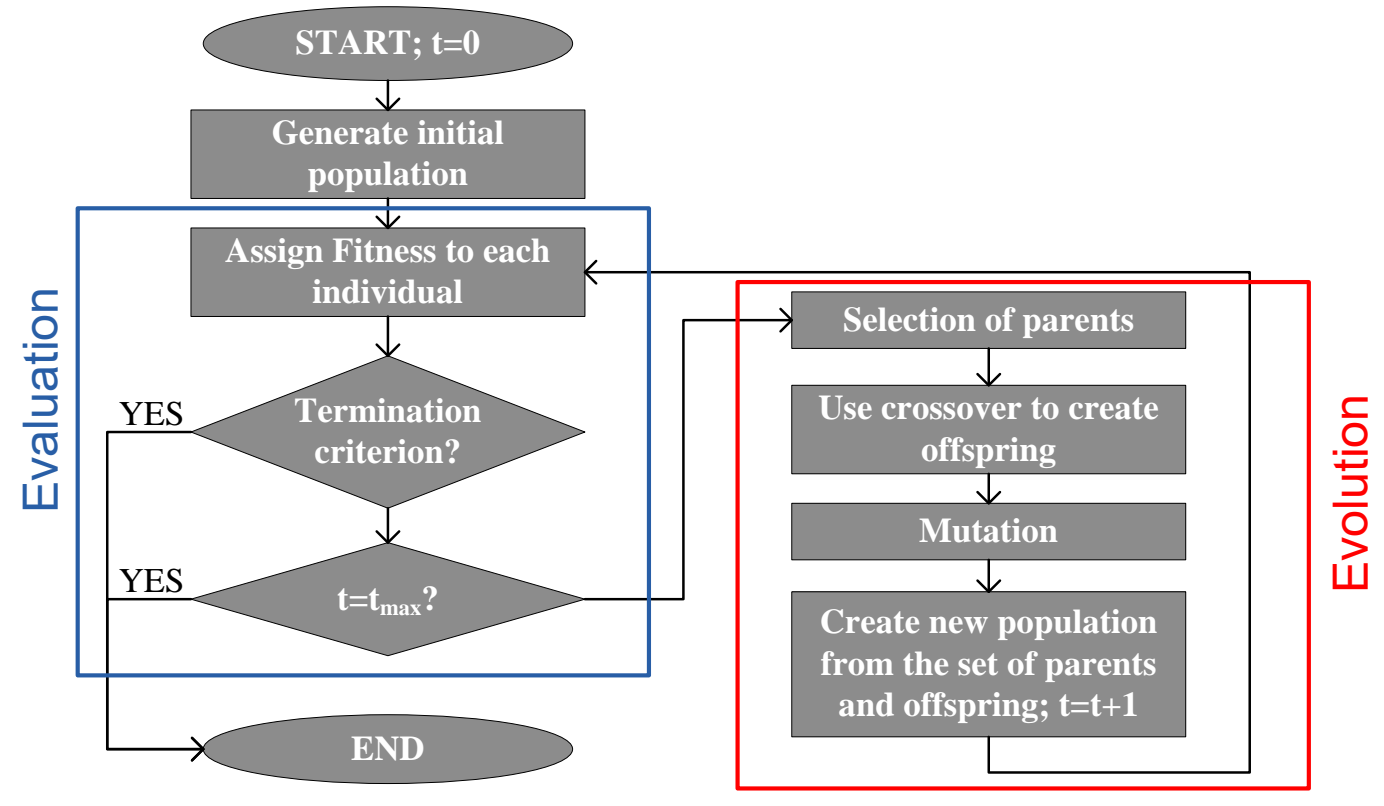

Fig. 1. Genetic algorithm

In the seventies of the twentieth century, genetic algorithm was proposed by J.H.Holland as an abstraction of appropriate genetic processes. A decade later, genetic algorithms became one of major rapidly developing fields of informatics and artificial intelligence. The basic procedure of genetic algorithm can be seen in Figure 1.

The main advantages of genetic algorithms include:

- They do not require any special knowledge about target function, they are universal.

- Genetic algorithms have very good results with problems with a large set of possible solutions.

- Versatility for a variety of optimization problems.

Disadvantages include:

- They do not find optimal, but feasible solution.

- The implementation of the algorithm, the representation of solutions and the formulation of evaluation function can be difficult.

- If there is a specialized algorithm for a particular problem, which uses some knowledge about the problem, it usually surpasses the genetic algorithm both in speed and quality of the solution [1].

\section{Usage of genetic algorithms in industry}

Out of many application fields we can mention the following examples:

- Design of products, their components or materials

- Robotics

- Logistics

- Job scheduling

- Facility layout design and optimization

- Balancing manufacturing and assembly lines

- Machining

- Data mining 
Genetic algorithms found their use in design of racing and also regular vehicles. The struggle to create faster, lighter, safer, and environmentally cleaner and fuel efficient vehicles can be greatly accelerated by computer modeling and simulation, which use this kind of algorithm. With suitable application, they can replace time-consuming testing in wind tunnels, or laboratory experimentation with polymers. In paper "Optimizing the performance of a Formula One car using a Genetic Algorithm" [2] is described the use of a genetic algorithm to optimize 66 setup parameters (i.e. camber settings, ride height, toe in settings, radiator size, tire pressure, gear ratios) for a simulation of a Formula One car and performance improvements are demonstrated.

Another fast developing application of genetic algorithms is the maximization of use of the potential of whole variety of materials. The main aim is to optimize structural and functional design of buildings, facilities, plants, machines and equipment. Among these kinds of applications we can find design of heat exchangers, antennas, turbines, or robot effectors [13], [16].

In logistics, they have found use, for example, in the traveling salesman problem. With the use of genetic algorithms we are able to plan the most efficient route, correct timing to avoid rush hours, and maximize the use of transport vehicles, which can be very useful for freight companies.

Out of many other fields in which genetic algorithms have found their use we can mention, for example, robotics, encryption, criminalistics, computer games, finance or marketing [24].

In the fields of industrial engineering we can also find many potential areas for application of genetic algorithms [8]. In the following section we would like to present applications in the design and planning of production systems which have been developed, or currently under development at our university, at the Department of Industrial engineering.

\section{Production planning}

The first application is production scheduling. In dissertation thesis Production scheduling with the support of simulation and evolutionary methods [3] a modular system methodology for job shop scheduling with the support of simulation and evolutionary methods was proposed. In this methodology scheduling is defined as a sequence of steps, which are divided into three main parts:

1. Generation part - Generation of raw schedule using priority rules.

2. Evaluation part - Evaluation of the schedule using a simulation model.

3. Optimization module part - Schedule optimization using genetic algorithms [3].

The optimization module part tries to find an optimal schedule according to defined criteria, which are expressed in fitness function. Input data and results are displayed in MS Excel environment, wherein communication between Excel and simulation software runs through ActiveX interface. Optimization module itself is a part of the Plant Simulation software, developed by Siemens. In this software both the simulation and the optimization take place [8].

Problem closely linked to production scheduling, also approached through genetic algorithm is Assembly Line Balancing Problem. We can talk about General Assembly Line Balancing Problem (GALBP) in case if it takes into account not only precedence constraints but also other attributes and limitations [17], [18]. Thus widespread problem includes solution of lines with mix-model production, lines with parallel workstations, U-shaped lines, lines with differently equipped workstations and so on. A common feature of most line balancing problems is that one predefined precedence graph represents all possible precedence constraints between the operations. However, in real industry problems, there may be some parts of the manufacturing process replaced with alternatives, so there may be more variants of manufacturing process procedures. This is possible in many cases either assembly or disassembly of products for which there are multiple variations of production. So there is large space with possible solutions to the problem and it is needed to have effective tool for finding solution close to the optimum [19], [20].

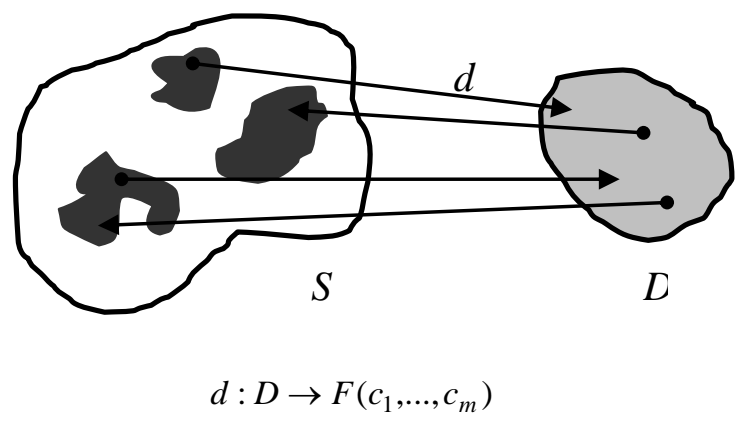

Fig. 2. Transformation d between spaces S and D [7]

In the genetic algorithm for solving line balancing problem it is needed to use the technology of decoder. Its use leads to the fact that the chromosome is not seen as a coded solution, but rather as information, which makes construction 
a feasible solution possible. Chromosome represents a sequence of operations, which will be assigned to workstations. So instead of searching space $S$ and its subsets it is possible by using an appropriate representation to create a completely different searching space D. So decoder d serves as a transition between individuals of space $S$ and their images in the set of feasible solutions $F\left(c_{1}, \ldots, c_{m}\right) \subseteq S$ (Figure 2).

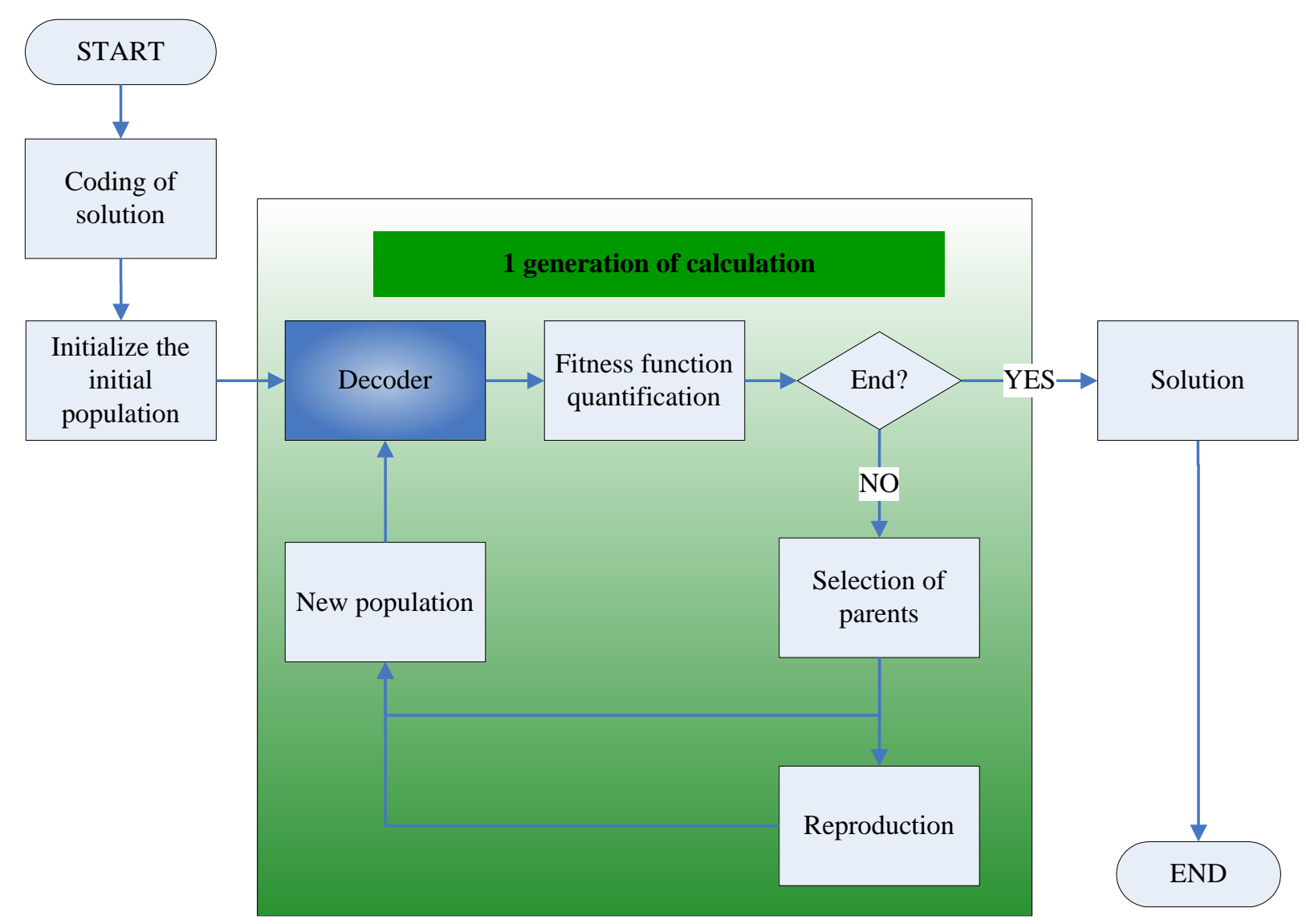

Fig. 3. Application of GA in line balancing problem

In the paper „Acquiring knowledge needed for pull production system design through data mining methods“ [22], the genetic algorithm is used to obtain data on status of work in progress and the number of completed orders based on the combination of number of Kanban cards kb1, kb2 and kb3. These cards circulate in three circuits - Supplier (kb1), Transport $(\mathrm{kb} 2)$ and Workplace $1(\mathrm{~kb} 3)$. The aim of the solution was to formalize relations that describe the impact of the selected combination of numbers of Kanban cards on the amount of work in progress and the numbers of finished orders. The maximum number of Kanban cards was set to $\max \{\mathrm{kbi}\}=30$. Utilization of genetic algorithms in this case reduced the number of simulation runs from 27000 to 1040 for optimization in terms of the amount of work in progress and 880 in terms of the number of finished orders. Matlab and Simulink environment were used for optimization through genetic algorithms [10].

\section{Design of production system layout}

Another area of application of genetic algorithms is the design and optimization of a plant or a facility layout. In general, we can define the facility layout problem as the search for the best arrangement of physical objects, which ensures the most effective operation of these facilities [5], [6], [9].

Currently, within dissertation thesis solved at the Department of Industrial Engineering at University of Zilina, system for plant layout design is being developed, utilizing genetic algorithms and Matlab/Octave environment. At this stage, input and results are transferred from/to Excel spreadsheet, where simple user interface was created. In the spreadsheet, we input parameters such as number of machines, dimensions, types and probabilities of genetic operators or intensities between workstations/machines (Figure 4). 


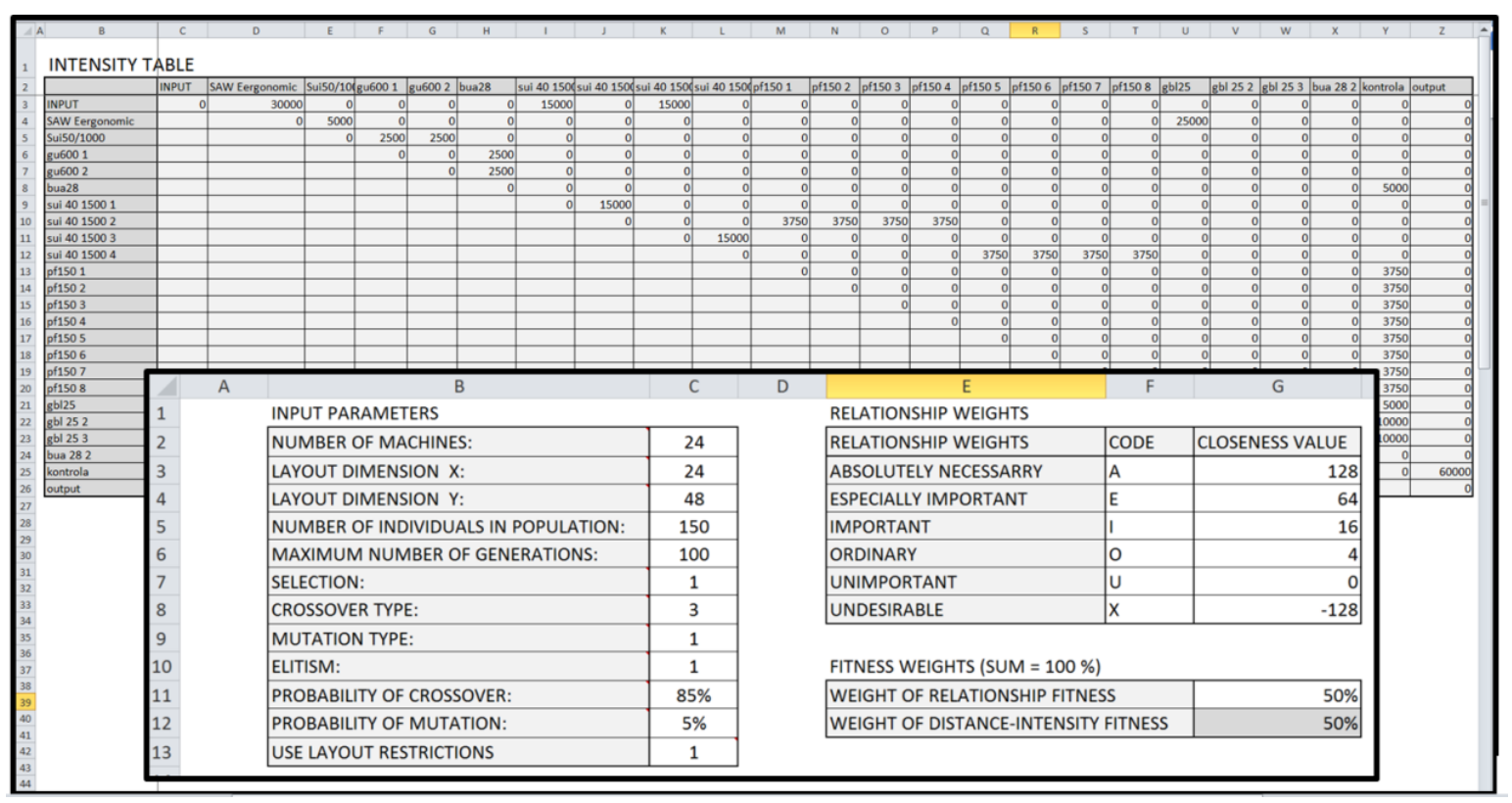

Fig. 4. Input sections of spreadsheet

After setting the input parameters we run the layout generator. It is important to note, that the algorithm itself is coded to work with both Matlab and Octave, where GMU Octave is distributed under general public license. The algorithm creates initial solutions in specified quantity and performs evolution [11], [12], [23]. After the run, results are transferred back to Excel. Returned are X and Y coordinates, cost and graphic interpretation. Following figure shows average and best fitness values during the run, final solution visualization in Excel.

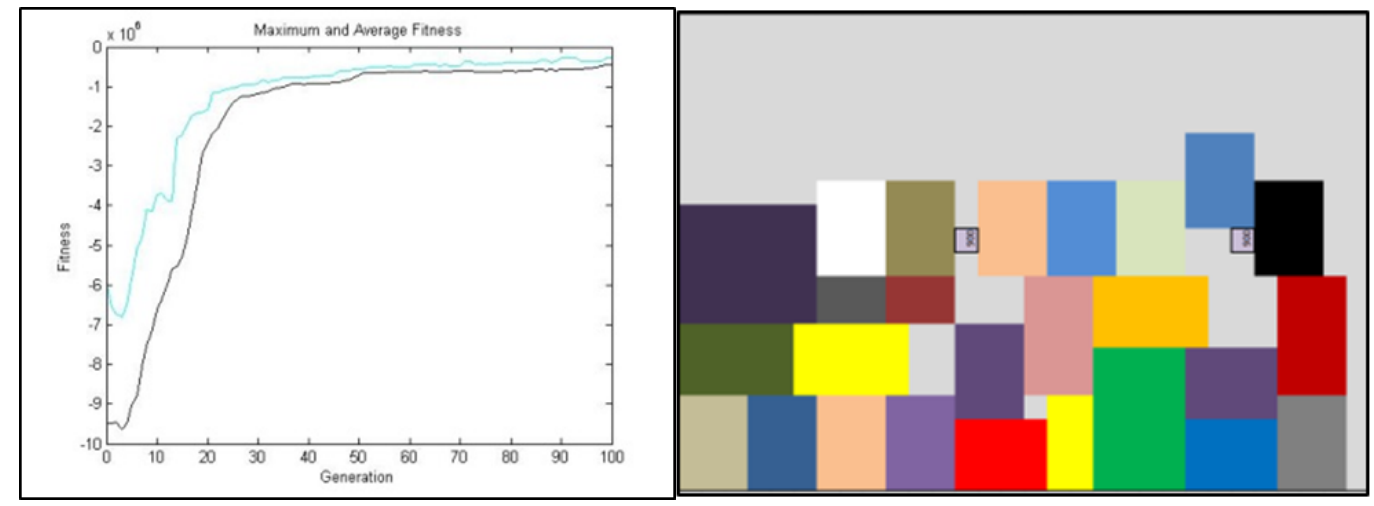

Fig. 5. Best and average fitness of the run and the final solution in Excel

Next steps will include adding third dimension - height to chromosome, to check if machine fits in the particular area of the facility and interconnection with AutoCAD software with Tecnomatix extensions FactoryCAD and FactoryFLOW, where obtained plant layout will be constructed and evaluated.

FactoryFLOW extension allows performing static evaluation of the proposed layout such as material flow analysis, aisle congestion analysis or capacity verification and create graphical representation of the results (i.e. Sankey diagram, D-I chart). With FactoryCAD extension, we can insert 3D models of machines in *.JT format, thus creating a 3D model of machine layout with the ability to perform area analysis. Also, thanks to support of SDX (Simulation Data eXchange) format, we can connect the layout with Plant Simulation software, to perform dynamic analysis.

\section{Simulation and verification}

In thesis , Simulation of the production system with the use of evolutionary methods “[4] a concept of simulationoptimization system with genetic algorithm has been designed and verified. Application named GAsfos 2 is presented, which cooperates with the simulation software Witness to optimize production system. Application is programmed in Visual Basic 6.0 and uses the core created with GAlib library. This library, which includes tools for using genetic algorithms, is programmed in $\mathrm{C}++$ and is available for free for academic purposes. The application consists of: 
1. GAsfoS2 - user interface.

2. GAworker - core, which uses genetic algorithms.

3. Valuator - used for communication between Witness and GAworker core, using OLE interface.

The application works as follows: When the GAsfos2 starts, through application it also starts Witness software with selected simulation model. The size of population, number of generations, simulation time and other factors affecting the course of optimization can be adjusted. After starting the optimization, GAworker creates zeroth generation, which is recorded to the communication and evaluation interface - Valuator. Subsequently, the model is set in Witness and the simulation is launched. After its completion, the model is evaluated and GAworker creates a new population, using roulette mechanism. After every generation, the results are recorded into Valuator. Process runs until one of the termination conditions are met - the maximum number of generations, or achieve desired values. Figure 6 shows the working principle of GAsfos2.

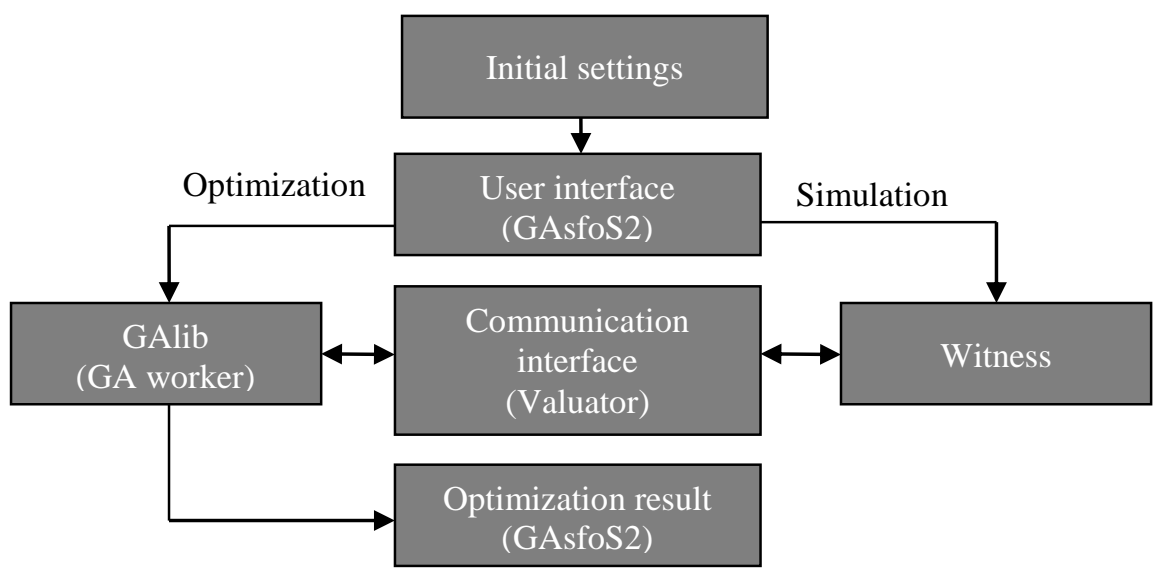

\section{Conclusion}

Fig. 6. Working principle of GAsfoS2 [4]

Previously mentioned solutions were proposed independently within their fields (simulation, scheduling, balancing, layout design). Our goal in the next stage is to integrate these solutions into one cooperative system. As the first step we will focus on integration of the plant layout design with the simulation system GAsfoS2, where the whole concept will be built on SIEMENS PLM solution Tecnomatix [21]. This means, that GAsfoS2 will have to be adapted to use Plant Simulation instead of Witness software. This concept will enable to solve facility layout problem with genetic algorithm, evaluate obtained solution both, statically and dynamically and also within the simulation run, use genetic algorithm to optimize the production system. The whole concept can be seen in Figure 7.

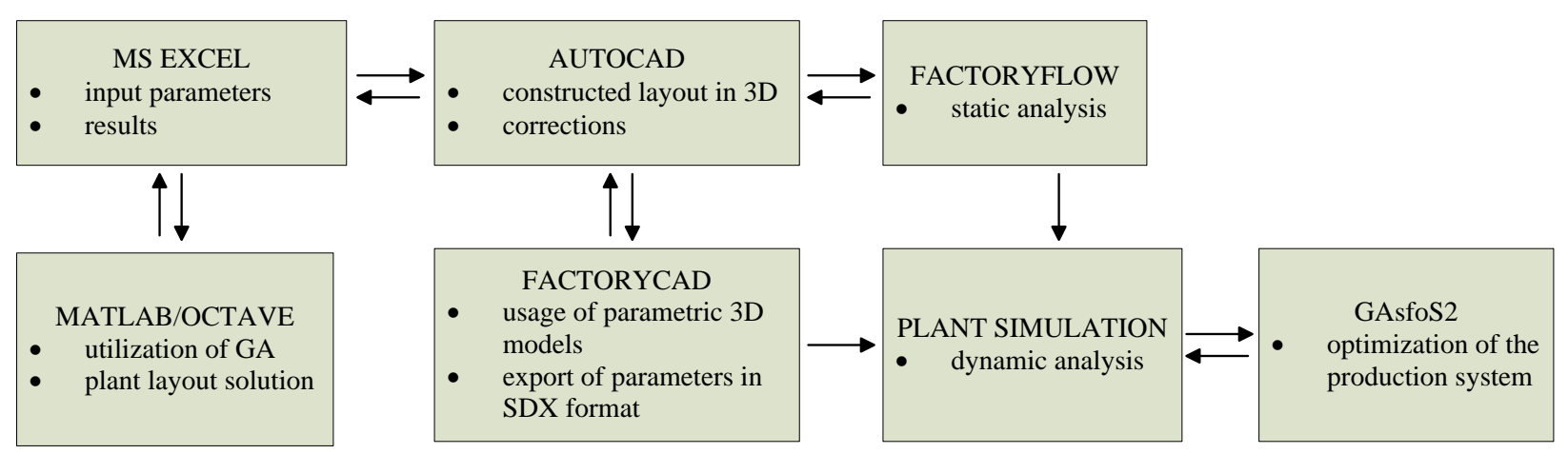

Fig. 7. Proposed concept of integration of genetic algorithms, plant layout design and simulation

The paper discusses genetic algorithms, and their utilization in the fields of industrial engineering, focusing on applications developed at the Department of Industrial Engineering, at the University of Zilina.

Genetic algorithms can be classified as an evolutionary stochastic search technique. They are generally applicable and can be suitable alternative to conventional methods mainly when solving global optimization problems, where there is a large number of possible solutions, solution set being too large to solve the problem using deterministic or enumerative methods. Taking into account the development of computer technology, we can assume that computing speed will increase and therefore, the use of genetic algorithms seems to be a promising area of research.

Based on this conclusion, genetic algorithms were utilized in various applications developed within research activities of the Department of Industrial Engineering, which were presented throughout the paper. Currently, integration of genetic algorithm within plant layout design and simulation is being developed, where the final aim is to provide user 
with plant layout proposed by a genetic algorithm, constructed in 3D, with the possibility to perform both, static and dynamic analysis with the option to optimize production system - also with the use of genetic algorithms. This can contribute to significant reduction of the time necessary to design and verification of the manufacturing system within the Digital Factory concept.

\section{Acknowledgements}

This paper was made about research work support: KEGA 065ŽU-4-2014.

\section{References}

[1] J. Hynek, "Genetic algorithms and genetic programming," Grada publishing a.s. Prague,2008, pp. 5-30. ISBN 9878024726953

[2] K. Wloch and P. J. Bentley, "Optimising the performance of a Formula One car using a genetic algorithm", The $\begin{array}{llll}\text { UCL Department of Computer } & \text { Science, } & \text { April } & \text { 2004, }\end{array}$ http://www0.cs.ucl.ac.uk/staff/P.Bentley/WLBEC1.pdf.

[3] S. Figa, "Production scheduling with the support of simulation and evolutionary methods," [Dissertation], Zilina, 2012 .

[4] M. Heglas, "Simulation of the production system with the use of evolutionary methods " [Diploma thesis], Zilina, 2011.

[5] N.F.B.Saleh and A.R.B. Hussain, "Genetic Algorithms for Optimizing Manufacturing Facility Layout,"2008, [Online] http://comp.utm.my/pars/files/2013/04/Genetic-Algorithms-for-Optimizing-Manufacturing-FacilityLayout.pdf.

[6] G. Suresh, V.V. Vinod and S. Sahu, "A genetic algorithm for facility layout," Int. Journal of Production research, Vol 33, No. 12., pp 3411-3423, 1995.

[7] B. Rekiek, A. Delchambre, “Assembly line design”. London : Springer, 2006. ISBN 978-1-84628-112-9.

[8] Kumar, Abdhesh and Pachauri, Praveen. Optimalization drilling sequence by genetic algorhitms. International journal of scientific and research publications. 2012, Vol. 2, 9. ISSN 2250-3153.

[9] Heragu, S. S. (2006) Facilities Design, Second ed., Louisville: iUniverse, Inc., 2006, 197-199 pp. ISBN: $978-$ 0595359387

[10] Rajasekharan, M., Peters, B. A., Yang, T. A genetic algorithm for facility layout design in flexible manufacturing systems. 1998, International journal of Production research, Vol. 33,No. 1, 95-110pp. ISSN 0020-7543

[11] Saleh, N.F.B., Hussain, A.R.B. "Genetic Algorithms for Optimizing Manufacturing Facility Layout,” 2008, [Online] Universiti Teknologi Malaysia [Avalible:] http://comp.utm.my/pars/files/2013/04/Genetic-Algorithms-forOptimizing-Manufacturing-Facility-Layout.pdf.

[12] Schiffauerova, A., "Layout design IV.", 2013. [Online]. Concordia University, Montreal [Available:] http://users.encs.concordia.ca/ andrea/indu421.html.

[13] D.E. Goldberg, "Genetic algorithms in search, optimization and machine learning," Addison-Wesley Professional, 1989, 432p., ISB 9780201157673

[14] D.Simon: "Evolutionary optimization algorithms," Wiley, 2013, 772p., ISBN 9780470937419

[15] J.H.Holland, "Adaptation in Natural and Artificial Systems: An Introductory Analysis with Applications to Biology, Control, and Artificial Intelligence,” A Bradford Book, 1992, 211 p., ISBN 9780262581110

[16] M. Affenzeller, et. al. "Genetic Algorithms and Genetic Programming: Modern Concepts and Practical Applications (Numerical Insights)," Chapman and Hall/CRC, 2009, 379 p. ISBN 9781584886297

[17] N.Boysen, M.Fliedner and A.Scholl: "A classification of assembly line balancing problems." European Journal of Operational Research, in press, 2006.

[18] N.Boysen, M.Fliedner and A.Scholl: “Assembly line balancing: Which model to use when?” International journal of production economics, 11(2), 2008. 509-528.

[19] E.Falkenauer: "Line Balancing in the Real World, International Conference on Product Lifecycle Management", 2005, 360-370.

[20] A.Scholl: "Balancing and sequencing of assembly lines." Physica, Heidelberg, 1999.

[21] R.Furmann and A. Štefánik: "Progressive solutions to support the design of production and logistics systems developed by the company CEIT SK, s.r.ro.”, In: Produktivita a inovácie : bimonthly magazine of University of Žilina in cooperation with the Slovak productivity center and the Institute for Competitiveness and Innovation, ISSN 1335-5961. - Roč. 12, č. 2 (2011), s. 3-5.

[22] Horák, Filip and Bubeník, Peter. "Acquiring knowledge needed for pull production system design through data mining methods", Industrial engineering 2013 : International student scientific conference. 2013, pp. 33-36.

[23] Kia, R., Khaksar-Haghani F., Javadian N. and Tavakkoli-Moghaddam: "Solving a multi-floor layout design model of a dynamic cellularmanufacturing system by an efficient genetic algorithm." In: Journal of Manufacturing Systems, Vol. 33. No. 1; 2014. s. 218-232. ISSN: 0278-6125.

[24] Saber M. Elsayed - Ruhul A. Sarker - Daryl L. Essam: "A new genetic algorithm for solving optimization problems" In.: Engineering Applications of Artificial Intelligence, Volume 27, January 2014, Pages 57-69, ISSN: 09521976. 